\title{
Including Accessibility Within and Beyond Undergraduate Computing Courses
}

\author{
Annalu Waller \\ School of Computing \\ University of Dundee \\ Dundee DD1 4HN Scotland \\ +44 (0)1382 388223 \\ awaller@computing.dundee.ac.uk
}

\author{
Vicki L. Hanson \\ School of Computing \\ University of Dundee \\ Dundee DD1 4HN Scotland \\ $+44(0) 1382386510$ \\ vlh@computing.dundee.ac.uk
}

\author{
David Sloan \\ School of Computing \\ University of Dundee \\ Dundee DD1 4HN Scotland \\ +44 (0)1382 385598 \\ dsloan@computing.dundee.ac.uk
}

\begin{abstract}
This paper presents a unique approach to undergraduate teaching in which accessibility topics are completely integrated throughout the curriculum, treating accessibility not as a separate topic, but rather as an integral part of design and development. Means of accomplishing this integration throughout the entire four-year curriculum are presented. We also describe how our expertise in accessible design has extended beyond the education of computer science and engineering students to include Web content authors across campus.
\end{abstract}

\section{Categories and Subject Descriptors}

K.4.2 [Computing Milieux]: Computers and Society - Assistive technologies for persons with disabilities. K.3.2 [Computing Milieux]: Computers and Education - Curriculum.

\section{General Terms}

Design, Human Factors, Legal Aspects.

\section{Keywords}

Accessibility, Inclusion, Higher Education, Older Adults, Disability.

\section{INTRODUCTION}

ACM, as part of its code of ethics and code for professional conduct, emphasizes the need for computing not to exclude people on any basis, specifically citing disability in this regard [2] [15]. This goal of inclusion applies both to a need to create accessible technology and a need to create accessible learning environments in computing education.

Worldwide there is ever increasing recognition that products, services, and ICT must be accessible. This recognition has led to the creation of numerous accessibility guidelines and the adoption of accessibility regulations by many countries. USACM, the

\footnotetext{
Permission to make digital or hard copies of all or part of this work for personal or classroom use is granted without fee provided that copies are not made or distributed for profit or commercial advantage and that copies bear this notice and the full citation on the first page. To copy otherwise, or republish, to post on servers or to redistribute to lists, requires prior specific permission and/or a fee.

ASSETS'09, October 25-28, 2009, Pittsburgh, Pennsylvania, USA.

Copyright 2009 ACM 978-1-60558-558-1/09/10...\$10.00.
}

policy arm of ACM, has been involved in the creation of usability statement about the Internet, emphasizing the need to make the Internet accessible to all [33]. Despite such widespread attention, accessibility remains a goal that far too often is not achieved.

A number of factors contribute to lack of accessible products and services, but undeniably one important issue is lack of knowledge among designers and developers about how to develop, or even awareness of the need to develop, accessible technologies. This paper discusses how topics of accessibility and inclusion are integrated into one university undergraduate curriculum. This emphasis has been part of the core teaching components at the university for several years. Computing students graduate not only with expertise in core computing skills, but with knowledge and experience in accessibility, technology to assist disabled people, and knowledge of the importance of user involvement throughout the development process. This is a package of skills that has served them well.

This paper is organized as follows. First the context for this curriculum is discussed in terms of other curricula for inclusion and accessibility in higher education. Next the philosophy and our model of embedding accessibility topics throughout a computing curriculum is detailed. A description of how accessibility is woven into teaching modules is presented, along with information about related projects that reinforce the accessibility and inclusion information covered more formally in coursework. It is argued that this approach, which considers accessibility as integral to a computing curriculum, not as a separate course, provides an exemplary method for training of designers and developers. We also describe how this approach has been extended more widely across campus to guide and influence the teaching and support of accessible Web design to staff in a range of roles, and how this experience feeds back into our core teaching activity.

\section{BACKGROUND}

In terms of teaching computer science and programming to disabled students, a few specific efforts have been reported [6] [32]. Smith et al., [32], for example, describe tools that enable students who are screen reader users to navigate hierarchical structures required for understanding complex code. Notably, a current National Science Foundation (NSF) initiative aims to increase the participations of students with disabilities in STEM (Science, Technology, Engineering, and Mathematics) areas [1]. 
This initiative, AccessComputing, provides examples of a number of best practices for inclusion in these sciences.

The goal of teaching accessible design practices at the undergraduate level has recently been gaining much attention also. Reasons for this attention include not only the growing number of worldwide standards and regulations governing accessible technologies, and the corresponding increase in demand for skills in accessible technology development, but also the need to address ethics and social responsibility in ICT innovation. Interestingly, it has been suggested that attention to accessibility issues might serve to attract female students to these science and technology fields by demonstrating how technology can address social issues [12].

Accessibility is often taught within the subject area of HumanComputer Interaction (HCI) [13] [18] [21] [22] [29]. More in depth consideration of accessibility and inclusion has been given in specific - typically advanced -- modules (courses) that have been created on this topic [11] [19] [20]. Liffick [19], for example, developed a course, complete with assistive technology (AT) lab, to familiarize students with how disabled users interact with computers. Ludi [20] includes specific training on requirements gathering related to accessibility in an advanced Engineering course.

Particularly effective have been courses in which students experience the needs of disabled users through the use of assistive technologies [4] [11]. Also, studies that have examined the use of projects to teach accessibility have found demonstrable benefits [3] [12] [14] [20]. Specifically, projects involving accessibility requirements or working with disabled users have been shown to significantly increase awareness of accessibility issues and designing to meet the needs of a diverse population.

For example, Mankoff initiated an Assistive Technology course at Carnegie Mellon University in the United States [21]. This course considered both Web and desktop accessibility for a number of disabilities and contained the interesting feature that all students were required to do a service project as part of the course. This service project provided students with experience is working with users of the technology.

Another exemplar course is one that Carter \& Fourney began at the University of Saskatchewan in Canada [4]. The unique feature of this course was its development of a series of Accessibility Demonstration Experiences (ADEs). These ADEs provide practical experiences for students to understand the needs of disabled users and to work on accessibility solutions.

A recent workshop in the UK was convened on the topic of Implementing Inclusive Design Education. ${ }^{1}$ Information presented at the workshop indicated that universities in 18 European countries reported having modules or elements related to inclusion or accessibility in their curriculum [16]. Particularly interesting from that workshop was the consideration of a new MSc programme in Digital Inclusion at Middlesex University.

\footnotetext{
${ }^{1}$ Brunel University, April 30, 2009. Workshop Programme available at http://www.sparc.ac.uk/workshops/2009-04-30inclusive-design-education/programme.asp
}

What is common from these courses and elements within courses is that the teaching of accessibility is not fully integrated into the wider curriculum. Topics related to design for older and disabled populations are often considered as special topics within an HCI course, or, in other cases, are given more intensive consideration as a separate course. They appear as add-ons or special topics; they are not treated as an integral part of education in computing, although arguments have been put forward for teaching accessibility topics early in a computer science curriculum [5] [12].

It is in this context that we describe a holistic approach to including accessibility principles throughout the entire undergraduate curriculum - indeed, as part of the larger university educational setting.

\section{AN INCLUSIVE PROGRAMME}

The School of Computing at the University of Dundee is internationally recognised as a centre for the development of accessible technologies for disabled people. Over the past 30 years, researchers at the School have been involved, for example, in work on aspects of augmentative and alternative communication (AAC), acceleration techniques (e.g. predictive text and disambiguation), Web accessibility, memory prompts for ageing and dementia, and dyslexia research [26].

This specialist research feeds back into undergraduate courses with ongoing emphasis on considering accessible design and indepth exploration of the relevant issues throughout third and fourth year. In this way, accessible design principles are integrated throughout the undergraduate degree programme, with the aim of having students regard accessibility as integral to software design and development. An overview of the programme is shown in Table 1. The following sections discuss the elements in detail.

Gellenbeck [12] articulates a strategy for integrating accessibility discussions throughout a computer science curriculum. Inspired by a report for including ethics and social responsibility in the curriculum [23], this strategy includes early introduction of key principles, continued discussion of these principles in most courses, integration of relevant topics within courses, and appropriate coverage of the topic. We note that the curriculum we describe can be said to meet with this strategy.

The needs of the older and disabled user have always been a part of the teaching in all undergraduate and most postgraduate degree programmes offered by the School of Computing. The underpinning teaching about inclusion and accessibility in these programmes is achieved implicitly and explicitly through:

- Encouraging students to grasp the philosophy of accessible design through following the principles of user sensitive inclusive design, pioneered within the school - the needs of older and disabled people are integral to any consideration of usability without necessarily compromising on functionality or creativity;

- $\quad$ Embedding practical usability and accessibility material in modules such as Web design and internet programming, taking a pragmatic approach to accessibility rather than simply referring to guidelines or pseudo-'standards'; 
- Adopting a research-led teaching approach in which state-of-the-art research in assistive and accessible technology are used as exemplars;

- Providing lectures by experts with real-world experience in accessible design throughout the degree program.

- Expecting that students will view user diversity as the norm as opposed to a special case, e.g., regular coursework is marked down if user diversity is not considered.

\subsection{First and Second Year}

In the formative years students are exposed to issues of diversity and inclusivity, giving them an understanding that not all users will necessarily be the same as them, and encouraging them to think about designing for others rather than themselves.

In the first year, introductory modules refer explicitly to accessibility. Thus, each student in the programme begins their coursework with a foundation in accessibility. In Introduction to Software Development, for example, user diversity is discussed when considering user needs, e.g., students are encouraged to validate user input and provide appropriate error correction as users with poor dexterity may mistype input data. Introduction to Data Structures and Algorithms similarly considers the topic as part of user needs. Further, students in this course engage in a final team translation project which is often framed as an assistive technology challenge. For example, the challenge has been to translate an AAC system into English. To accomplish this, they are introduced to AAC and symbol translation via the W3C. In the Web Authoring module there is specific consideration of accessibility, as, for example, exposure to guidelines and resources such as those provided by the Web Accessibility Initiative of the W3C [40]. The need to provide alternative text for images, for example, is presented as part of general design principles, rather than an extra feature.

In second semester, issues of accessibility are explicitly taught in Information Technology module with one of six lectures within the HCI component of the module being devoted to accessibility.

In the second year, modules on Information Technology (IT) in both semesters explicitly consider accessibility in the

Table 1. Summary of Undergraduate Curriculum and accessibility instruction.

\begin{tabular}{|c|l|}
\hline \multicolumn{2}{|c|}{ Undergraduate Curriculum } \\
\hline First Year & $\begin{array}{l}\text { Explicit teaching of accessibility in } \\
\text { introductory modules on software } \\
\text { development and data structures }\end{array}$ \\
\hline Second Year & $\begin{array}{l}\text { Accessibility issues in year-long } \\
\text { Information Technology and Applied } \\
\text { Computing modules }\end{array}$ \\
\hline Third Year & $\begin{array}{l}\text { Accessibility taught in HCI and Internet } \\
\text { programming modules, along with } \\
\text { practical experience and team projects }\end{array}$ \\
\hline Fourth Year & $\begin{array}{l}\text { Research Frontiers modules and } \\
\text { individual Honours projects }\end{array}$ \\
\hline
\end{tabular}

programming components and projects with the HCI components of the module. The importance of accessibility in programming is reinforced by a guest lecturer from a multinational engineering company. Each of these modules is compulsory for the School's Applied Computing degree. In addition, the second year Applied Computing modules address accessibility issues as an integral aspect of computing.

The HCI component of the IT module introduces students to a broad range of user-centred design approaches using real projects presented by experts. These projects range from large scale ethnography based projects designing ubiquitous technology to smaller projects focusing of specialised systems for disabled user. Students gain insights into conducting inclusive user-centred design with children, older and disabled people as well as specialised design of bespoke systems for people with more severe physical and/or cognitive impairment. Within the context of team projects, ethical considerations are introduced which encourage students to consider the impact and consequences of user-centred design.

\subsection{Third Year}

By third year the students should be well aware of accessibility issues and will have some understanding of the difficulties disabled and older people might experience using technology. In the third year, a combination of lectures, discussions and practical sessions, are designed to make students aware of the philosophy surrounding accessibility. Students are taught the real correlation between accessibility and usability and how considering accessibility helps to produce a more usable product for all. They are encouraged to consider the reasons why accessibility is important such as the legal implications, good design, technical/technological reasons and commercial reasons.

Issues related to accessibility are taught in courses on Software Engineering, Internet Programming, GUI Programming, HCI, and Databases.

\subsubsection{Explicit teaching on accessibility}

Seminars on accessibility are included in the HCI module alongside seminars on design techniques such as ethnography, design issues relating to specific user groups, e.g., older people and children. The accessibility teaching challenges the students' ideas of inclusion and encourages them to think of situations where conventional accessibility guidelines may not be appropriate. Real world conflicts are explored between accessibility and, for example, design goals, technological limitations, customer objectives and software objectives. This encourages students to explore all issues relating to end users and their goals rather than a blinkered following of a set of guidelines. Students are also asked to examine and discuss the trade-offs between good aesthetic design, sound software engineering and the need for accessibility, for example through mock debates on whether accessibility considerations stifle or spark creativity.

\subsubsection{Examples of practical experience}

During practical sessions students gain an understanding of the extent of the difficulties experienced by users by taking part in exercises that effectively disabled them in different ways. They also gain practical experience with evaluating techniques for accessibility that they can use on their own software products. 
A recent example was the design of an email system. The "workshop session" consists of three separate sessions lasting up to 2 hours each. First, students were given "wish lists” written by older people about email systems, these lists detailed current problems with email systems and described the way in which people interact with their systems (e.g. the functionality they use). With these lists as prompts, students evaluated a current email program from a usability and accessibility perspective; second, students in groups of 4-6 were asked to design paper prototypes of a more accessible and usable email system for older people. Finally, a group of 6-7 older people were invited to the department and evaluate the student prototypes.

The results of this "workshop session”, particularly of the final evaluation session, are illuminating for students who may not appreciate the various complexities inherent in the design and evaluation of accessible systems until they themselves have experienced them. Paper prototyping not only enables the initial development to be rapid, it enables changes to be made during the evaluation period, these changes being easily visible to the students afterwards. The advantage of paper prototyping for testing issues like terminology is invaluable when designing for older novice computer users. Face-to-face meetings with a complicated user group, who may encompass a wide range of impairments, and the fact that students have focused on these users for a week, emphasizes the necessity to interact with users in order to design appropriately for them.

The evolution of student attitudes from the initial stages of email system evaluation to interacting with a group of older people, and properly coming to understand their needs and how they may differ from those of a twenty-year-old computing student, is dramatic. As well as involving students personally in issues of design for diverse user groups, the "workshop session” provides an excellent basis for referring back to during the rest of the course when usability engineering is discussed in some depth.

\subsubsection{Examples of team projects}

An important aspect of the third year HCI module is the team project which is conducted in parallel to the workshop sessions. Students choose their own projects - they are required to develop a series of prototypes which address usability issues relating to their chosen topic. The focus is on the use of appropriate design and evaluation methods. Students are assessed on the process rather than the end product, with an emphasis on user involvement. This module is compulsory for third year students of both the Applied Computing and Interactive Media Design degree programmes.

The projects are varied and imaginative. For example, one team bought a petrol pump handle (from eBay) and designed a usable petrol pump, while another team designed an interactive kitchen which would help students prepare meals. Both teams took the needs of older and disabled people into consideration as a matter of course. Neither project was an 'inclusion' project, but the natural way in which diverse user needs were addressed reflects the extent to which students have internalized the concept of inclusive design by the third year.

\subsection{Fourth (Final) Year - Student Projects}

Specific focus on accessibility topics is given in elective coursework in the fourth year. A module entitled Research
Frontiers allows students to select two or more seminar series from a range of specific topics. Included in that series are two offerings related to accessibility.

The first offering, Accessibility and Computing, covers a number of topics in accessibility. Lectures on user involvement in research, language and hearing loss, cognition, ageing, motor disability, and vision loss comprise the core. Within that, students are made of a number of critical issues for user populations and presented with a range of current research topics in each of those areas. Final research presentations allow students to choose a research area of their interest for further exploration.

The second offering, Aspects of Assistive Technology and Augmentative and Alternative Communication (AT\&AAC), provides an in-depth look at the design of specialised systems for people with complex disabilities. This module provides an overview of AT before focusing on the state of the art in the area of AAC, including research done in the School [37]. A unique aspect of this module is the site visit to a local smart house where students are given a hands-on introduction to smart house technology. A second visit to a local AAC service gives students the opportunity to interact with several adults, all of whom have complex communication needs. Students return from this visit with a real understanding of the need for better design of AAC systems, the heterogeneity of this population group, the limitations of design for all and the inherent cost of specialised equipment. Moreover, students gain an insight into the world of complex disability which they explore when preparing and presenting on a topic of their choice. This module is complimented by a third seminar series on natural language processing which focuses on the research addressing various communication rate acceleration techniques, many of which have been developed in the School.

Student projects have become a mainstay in the education of computing and engineering students. It is within this context that students their final year of our degree programme undertake a major software design and development project (taking up roughly half their time over the year). These student projects frequently involve disabled users, older adults, or an otherwise diverse range of people as end users, and is another aspect where 'accessible thinking' can be put into practice throughout the design lifecycle. The assignment does not require addressing an accessibility topic, although many students choose a project in this area. Notably, many projects, while not specifically on accessibility issues, incorporate accessibility features as a result of the School's curriculum.

Examples of recent student projects include:

- $\quad$ TouchType Hero, an application designed to train users of any generation and computer experience how to touch type, included features that addressed visual disability. The software allowed the user to play along with any audio CDs.

- An MSc project to design a website for an international charity ensured that it was accessible in order to demonstrate best practice.

- An alternative interface for Instant Messaging designed to meet the needs of older adults was designed and tested [27]. The alternative interface used a metaphor 
design for ease of use and was successfully tested with older adults.

- $\quad$ Several projects have investigated how non-text AAC systems, e.g., Blissymbolics, can be enhanced using natural language techniques and mobile communication technology [24] [38] [39] ${ }^{2}$.

- An extension to the STANDUP joke generation system that involved children as designers [25].

- A quiz-based approach to Web accessibility evaluation software - a tool that reviewed Web pages for accessibility and prompted the user to consider which solution would be the most appropriate

These examples show that student projects cover a wide variety of topics related to disabled users and older adults.

\section{THE LEARNING ENVIRONMENT}

For accessibility to be taken seriously in a university environment, the School of Computing has long considered it essential that the environment itself is made as accessible as possible to all staff and students, regardless of disability. Given the nature of much of the research carried out in the department, there has always been an acute awareness of accessibility needs as well as an understanding of current thinking and technological developments in the area. The School of Computing's Disability Support Officer (DSO), therefore liaises closely with University disability support, and separately developed and maintains a divisional Disability Policy and supplementary information for students with specific access needs [36].

The 'virtual' teaching and learning environment was also assessed in 2000 for accessibility by the Digital Media Access Group (DMAG), the School's in-house research and consultancy unit specialising in accessible and usable Web and software design, in 2000 [7]. At that time, each course of the Honours BSc in Applied Computing was evaluated for any potential accessibility problems. The review concentrated on identifying the pedagogical aims of each course, as well as identifying methods of teaching and assessment, such as the software used. This allowed identification of any courses that might require specific physical abilities for successful completion, and resulted not only in a report setting out a 'state of play' of accessibility, but encouraged staff to look at the accessibility of teaching and assessment methods and to consider accessible alternatives that preserve the pedagogical aims of the course. Additionally, supporting Web content, such as the departmental Web site and any other pages specific to a course, were evaluated and recommendations were made for their improvement.

Finally, the School's long-standing commitment to involving users throughout research efforts lead to the creation of a unique onsite learning opportunity for students. With the opening of a new building for the School in 2005, a User Centre was opened on the ground floor of the building [10]. This User Centre provides a place for older adults to regularly come to learn to use computers. In this sense, it serves to introduce older users to technology, similar to the work of a number of organizations

\footnotetext{
${ }^{2}$ Winner of the 2006 Young Scottish Engineer Award.
}

worldwide, such as Age Concern (UK), SeniorNet (US), and OldKids (China). The unique feature of this centre, however, is that the learning is a two-way street. Students working on projects are able to talk with the people at the centre to get feedback on their ideas. In many cases, this is quite illuminating to students who realize that their initial design ideas will not work with users other than themselves.

\section{TEACHING ACCESSIBILITY BEYOND THE UNDERGRADUATE DEGREE}

The skills and expertise contained within the School of Computing have been put to wider use, beyond taught degree courses. For example, DMAG has provided consultancy in accessible and inclusive Web and software design since 1999, working with clients in industry, education, government and healthcare sectors [4]. Shown in Table 2 is a summary of inclusion resources and activities at the university.

Through DMAG, the School also plays a lead role in promotion accessible technology design and use across the university as a whole. In common with other educational institutions in the UK, the University has legal responsibilities under the Disability Discrimination Act towards disabled staff, students, and members of the public [8] [9]; beyond this it recognises the benefits of using the Web and other ICTs to provide an optimally accessible teaching and learning environment. Thus there is a need to provide accessibility education to employees who create and maintain Web content, as well as advising central teams responsible for procuring and implementing systems supporting the publication of Web content.

\subsection{A Web Accessibility Service}

Prior to 2006, DMAG had been engaged on an ad-hoc basis to provide one-off Web accessibility audits and occasional staff training sessions on Web accessibility. Subsequently, this was formalised through the establishment of the Web Accessibility Support Service, funded by Student Services, and with a remit of supporting staff and central services in the aim of raising awareness and skills in Web accessibility.

The Service, run by DMAG, works closely with key accessibility stakeholders in Disability Support, Information and Communication Services, Learning and Teaching, and External Relations to provide a range of services raising the profile of Web accessibility at the University, at a strategic and individual level, and is active at a number of levels.

\subsection{Influencing University Accessibility Policy}

At a strategic level, the Service has always promoted a holistic and pragmatic approach to Web accessibility [17] [30]. This recognises the opportunities for enhanced inclusion for disabled people provided by the use of electronic resources to supplement or provide alternatives to more traditional means of providing access to information and experiences, while also acknowledging the benefits and practical challenges of inclusive electronic resource design.

This approach is echoed in the university's formal Web Accessibility Policy, drafted by the Service and accepted as formal policy in May 2008 which firstly promotes the use of the Web as a means to overcome existing barriers, and secondly 
promotes the avoidance of new barriers wherever possible when using the Web to provide access to information and experiences.

The Accessibility Policy is supported by a more detailed Definition of Best practice, which outlines key principles of accessible Web design, based on W3C WCAG 2.0 [34]. The aim of this resource, which will be regularly updated to reflect changes in best practice, is twofold:

1. as a first-stop resource on Web accessibility that is written with University staff in mind, but which can be used as an introduction to more comprehensive references such as WCAG 2.0;

2. as a working definition of an institutional accessibility baseline, which can be used to define a basic expected level of accessibility to be met by external contractors engaged in providing Web content and web publishing tools to the University.

\subsection{Raising Awareness and Skill Levels}

A number of activities have focused on raising awareness and skill levels in accessible Web design, supported by the Policy and Definition of Best Practice as described above. These include:

- Advice to the University's central Web team on accessibility issues relating to the redesign of the main University Web site, including accessibility reviews of new templates, and advice on use of multimedia and other non-HTML content to enrich information and experiences.

- Web Accessibility Training Workshops, run as part of the Staff Development programme. These explain the roles of assistive technologies, browser and authoring tools in creating an optimally accessible Web, introduce the principles of accessible Web design, and through practical exercises provide participants with accessible design and evaluation skills.

- Development of an online accessibility resource. A Web site supporting the work of the Web Accessibility Service has been developed, providing access to the Definition of Best Practice, supported by examples, plus additional resources on a variety of aspects of accessible Web design.

- One-to-one accessibility support: the service provides answers to accessibility queries via telephone and email, and also meets staff on request to review existing or in-development Web resources for potential accessibility issues.

- Meetings and events: occasional informal meetings are organized to discuss developments in accessible Web site design; these are aimed not only at informing staff of new techniques, but to encourage the formation of a Web development community that can share ideas and experiences across campus.

While not directly part of the activity of the Web Accessibility Service, DMAG has additionally provided training courses on user-centred Web design using HTML and CSS to doctoral students and postdoctoral researchers as part of the University's Generic Skills programme. Discussions are also underway with the Careers Service about provision of a similar course for graduate students.

\subsection{Procurement and Provision of Web Authoring Tools}

Awareness-raising amongst individual staff can be challenging. The service typically receives requests for advice and help either from people who have attended a recent event on Web accessibility or from authors who are already aware of accessibility issues, but know they would benefit from specialist advice, or have specific questions to ask. There is though the challenge of reaching out to those staff members who develop online resources but who are simply unaware of Web accessibility, or are too busy to attend events or develop skills or may not even consider themselves Web authors.

So, over time, the Service has increasingly focused on providing support on optimising the quality of tools used to publish Web content. By providing staff with the best possible tools to support accessible authoring out-of-the-box, the intended outcome is a reduced need for post hoc evaluation and repair activity, while also reducing the impact on accessibility of a lack of awareness of the issue amongst more hard-to-reach or hard-to-engage staff.

Various activities have taken place to assess the quality of accessibility support of existing tools available to staff to create Web content, including software for generating online surveys, exams and assessments, and software for creating e-learning resources. In each case, the W3C's Authoring Tool Accessibility Guidelines (ATAG version 1.0) [35] have been used as a baseline against which to measure tool support for accessibility; and reports focus on providing a recovery strategy which identifies how the impact of accessibility shortcomings can be managed through user education, changes in implementation, or through feedback to the tool developers. One such study carried out by the Service is described in more detail in [31].

The Service is also active in the University's Web Content Management System (WCMS) procurement project, charged with selecting a WCMS on which the University Web site will run. In addition to many other benefits, a WCMS has the potential to significantly reduce the burden of creating and maintaining optimally accessible Web content, particularly for users without

Table 2. Summary of university resources related to inclusion.

\begin{tabular}{|c|c|}
\hline \multicolumn{2}{|c|}{ University Resources for Inclusion } \\
\hline User Centre & $\begin{array}{c}\text { Students gain practical experience } \\
\text { working with older users in an informal } \\
\text { setting }\end{array}$ \\
\hline $\begin{array}{c}\text { Disability Support } \\
\text { Services }\end{array}$ & $\begin{array}{c}\text { Close working relationship between } \\
\text { School and university to ensure } \\
\text { accessible learning environment }\end{array}$ \\
\hline $\begin{array}{c}\text { Digital Media } \\
\text { Access Group }\end{array}$ & $\begin{array}{c}\text { Promoting and supporting creation of } \\
\text { optimally accessible content throughout } \\
\text { the university's Web presence }\end{array}$ \\
\hline $\begin{array}{c}\text { External Clinical } \\
\text { Services }\end{array}$ & $\begin{array}{c}\text { Close working relationship between } \\
\text { School and clinical services to ensure } \\
\text { exposure to real-life settings }\end{array}$ \\
\hline
\end{tabular}


expertise in Web design and accessibility. Thus, detailed accessibility considerations, including requests for evidence of ATAG conformance, were written into specification documents, and accessibility assessment played a significant role in the assessment of candidate WCMSs. At the time of writing, a WCMS has been chosen, and the work of the Web accessibility Service will focus on ensuring implementation of the system ensures that accessible authoring support is optimized.

\subsection{Measuring Impact}

Evaluation of the impact of the Service on accessibility awareness of staff and accessibility levels of University Web content is a significant task, and one that is ongoing, partly as a requirement of the Disability Equality Duty (DDA 2005, [8]). Limitations in funding and personnel mean the Service is unable to provide the all-encompassing institutional accessibility monitoring framework as described by WebAIM [41], while encouraging people to make accessibility enhancements to specific Web content is always an ongoing task. However, the adoption of a Web accessibility policy by senior management, and the increasingly prominent role of the Service in advising on central IT projects that have a significant role in Web publishing quality are two indicators that the Service is helping to ensure accessibility is a key consideration in the University's Web publishing strategy.

Through the Web Accessibility Service, the ultimate aim is to share and encourage best practice in accessible design and use of technology in education, research and public engagement such that an accessibility community of practice, as described by Seale [28], exists across campus.

\section{CONCLUSIONS}

By taking advantage of the research expertise within the School of Computing, the School faculty teaches accessibility throughout the undergraduate degree programme in a holistic way.

User sensitive design and accessible design techniques are integrated into a variety of modules throughout the curriculum. Offering a range of final year undergraduate projects which involve design of systems for users with specific access needs, also encourages 'accessible thinking' among all students in the programme. Ultimately the aim of the programme has been, and remains, the provision of an environment for learning computing in which awareness and knowledge of inclusion are fully integrated into the curriculum. Furthermore, through initiatives such as the Web Accessibility Service, the School aims to be active in sharing and promoting best practice in accessible and inclusive technology design and use across campus, supporting the University in creation an optimally accessible learning and working environment.

\section{ACKNOWLEDGEMENTS}

The writing of this paper was funded, in part, by a Royal Society Wolfson Merit Award to the second author.

\section{REFERENCES}

[1] AccessComputing. Available at http://www.washington.edu/accesscomputing/

[2] ACM code of ethics and professional conduct. 1992. Available at http://www.acm.org/constitution/code.html
[3] Buckley, M., Kershner, H., Schindler, K., Alphonce, C., and Braswell, J. 2004. Benefits of using socially-relevant projects in computer science and engineering education. In Proceedings of the 35th SIGCSE Technical Symposium on Computer Science Education, ACM, New York, NY, 482486.

[4] Carter, J. A. and Fourney, D. W. 2007. Techniques to assist in developing accessibility engineers. In Proceedings of the 9th international ACM SIGACCESS Conference on Computers and Accessibility (Tempe, Arizona, USA, October 15 - 17, 2007). Assets '07. ACM, New York, NY, 123-130. DOI= http://doi.acm.org/10.1145/1296843.1296865

[5] Cohen, R.F., Fairley, A.V., Gerry, D., and Lima, G.R. 2005. Accessibility in introductory computer science. In Proceedings of the 36th SIGCSE technical symposium on Computer Science Education. ACM Press, New York, NY, 17-21.

[6] Deibel, K. 2007. Studying our inclusive practices: course experiences of students with disabilities. In Proceedings of the 12th Annual SIGCSE Conference on innovation and Technology in Computer Science Education (Dundee, Scotland, June 25 - 27, 2007). ITiCSE '07. ACM, New York, NY, 266-270.

[7] Digital Media Access Group. 2009. Available at http://www.computing.dundee.ac.uk/ac_research/projectdetai ls.asp?id=41

[8] Disability Discrimination Act 2005. 2005. http://www.opsi.gov.uk/Acts/acts2005/ukpga_20050013_en_ 1

[9] Disability Discrimination Act 1995. 1995. Available at http://www.opsi.gov.uk/acts/acts1995/ukpga_19950050_en_ 1

[10] Forbes, P., Gibson, L., Hanson, V. L., Gregor, P., \& Newell, A. F. 2009. Dundee User Centre - A Space Where Older People and Technology Meet. In Proceedings of the 11th International ACM SIGACCESS Conference on Computers and Accessibility. ACM, New York, NY.

[11] Freire, A. P., Palva, D. B. P., Turine, M. A. A., and Fortes, R. P. M. 2005. Using screen readers to reinforce web accessibility education. Proceedings of ITiCSE'07. ACM, New York, NY, $82-86$.

[12] Gellenbeck, E. 2005. Integrating accessibility into the computer science curriculum. Journal of Computing Sciences in Colleges, 21(1), 267-273.

[13] Hanson, V. L. 2007. Inclusive thinking in computer science education. In Proceedings of the 12th Annual SIGCSE Conference on innovation and Technology in Computer Science Education (Dundee, Scotland, June 25 - 27, 2007). ITiCSE '07. ACM, New York, NY, 3-3. DOI= http://doi.acm.org/10.1145/1268784.1268787

[14] Horenstein, M., and Ruane, M. 2002. Teaching social awareness through the senior design experience. In Proceedings of the ASEE/IEEE 32nd Annual Frontiers in Education Conference. IEEE Computer Society Press, Washington, DC, S3D7 - S3D12. 
[15] IEEE-CS/ACM Joint Task Force on Software Engineering Ethics and Professional Practices. 1999. Software engineering code of ethics and professional practice (Version 5.2). Available at http://www.acm.org/serving/se/code.htm

[16] Keith, S., and Whitney, G. 2009. Examples of best practice in teaching of inclusive design. Paper presented at the SPARC Workshop on Implementing Inclusive Design Education (Brunel University, April 30, 2009). Available at http://www.sparc.ac.uk/workshops/2009-04-30-inclusivedesign-education/programme.asp

[17] Kelly, B., Phipps, L. and Swift, E. 2004. Developing A Holistic Approach For E-Learning Accessibility. Canadian Journal of Learning and Technology 30(3).

[18] Liffick, B.W. 2004. An assistive technology project for an HCI course. In Proceedings of the 9th Annual SIGCSE Conference on Innovation and Technology in Computer Science Education. ACM, New York, NY, 273-273.

[19] Liffick, B.W. 2005. An adaptive technologies course in a CS curriculum. In Proceedings of the 7th International ACM SIGACCESS Conference on Computers and Accessibility. ACM, New York, NY, 192-193.

[20] Ludi, S. 2007. Introducing accessibility requirements through external stakeholder utilization in an undergraduate requirements engineering course. In Proceedings of the $29^{\text {th }}$ International Conference on Software Engineering. IEEE Computer Society, Washington, DC, 736-743.

[21] Mankoff, J. 2006. Practical service learning issues in HCI. In CHI '06 Extended Abstracts on Human Factors in Computing Systems (Montréal, Québec, Canada, April 22 - 27, 2006). CHI '06. ACM, New York, NY, 201-206. DOI= http://doi.acm.org/10.1145/1125451.1125494

[22] Marcus, A. 2005. What would an ideal CHI education look like?. interactions 12, 5 (Sep. 2005), 54-55. DOI= http://doi.acm.org/10.1145/1082369.1082408

[23] Martin, C. D., and Weltz, E. Y. 1999. From awareness to action: Integrating ethics and social responsibility into the computer science curriculum. ACM SIGCAS Computers and Society, 29(2), 6 - 14.

[24] Millar, S. (2006). Blissymbolics on a PDA. Paper presented at the Young Researcher's Consortium, 11th International Conference on Computers Helping People with Special Needs, University of Linz, Austria, July 7-8, 2008.

[25] Moar, E., Waller, A., Black, R. (2008) Asking Children to design AAC devices. 13th Biennial Conference of the International Society for Augmentative and Alternative Communication, Montreal, Canada, 4-7 August 2008.

[26] Newell A. F., Carmichael, A., Gregor, P., Alm, N. and Waller, A (2008). Information technology for cognitive support. In A. Sears and J. Jacko (Eds.), The HumanComputer Interaction Handbook, Second Edition Lawrence Erlbaum, New Jersey, USA. 811-828.

[27] Prior, S., Arnott, J., and Dickinson, A. 2008. Interface metaphor design and instant messaging for older adults. In
CHI '08 Extended Abstracts on Human Factors in Computing Systems (Florence, Italy, April 05 - 10, 2008). CHI '08. ACM, New York, NY, 3747-3752. DOI= http://doi.acm.org/10.1145/1358628.1358924

[28] Seale J 2004. The Development of accessibility practices in e-learning: an exploration of communities of practice. ALTJ, Research in Learning Technology, 12(1) March 2004. Carfax Publishing: 51-63.

[29] Sears, A., and Jacko, J. A. (Eds). 2007. Human-Computer Interaction Handbook: Fundamentals, Evolving Technologies and Emerging Applications ( $2^{\text {nd }}$ Edition). Mahwah, NJ: Erlbaum.

[30] Sloan D., Kelly B., Heath A., Petrie H., Hamilton F. and Phipps L. 2006. Contextual Accessibility: Maximizing the Benefit of Accessibility Guidelines. Proceedings of the 2006 International Cross-Disciplinary Workshop on Web Accessibility (W4A) (Edinburgh, Scotland, 23 May 2006). New York: ACM Press, 121-131.

[31] Sloan D. and Walker D 2008. Evaluating the Accessibility to Disabled People of E-Assessment Tools. In: Proceedings of the 12th International Conference on Computer Aided Assessment (CAAC). Loughborough, UK, 8-9 July 2008.

[32] Smith, A. C., Cook, J. S., Francioni, J. M., Hossain, A., Anwar, M., and Rahman, M. F. 2004. Nonvisual tool for navigating hierarchical structures. In Proceedings of the 6th international ACM SIGACCESS Conference on Computers and Accessibility (Atlanta, GA, USA, October 18 - 20, 2004). Assets '04. ACM, New York, NY, 133-139.

[33] USACM. 2008. Policy statement on Internet accessibility. Available at http://www.acm.org/public-policy/accessibility

[34] W3C Web Content Accessibility Guidelines (WCAG) 2.0. 2008. http://www.w3.org/TR/WCAG20/

[35] W3C 2000. Authoring Tool Accessibility Guidelines 1.0. February 2000. http://www.w3.org/TR/WAI-AUTOOLS/

[36] Waller, A. 2006. Support for Students with Disabilities. Available at http://www.computing.dundee.ac.uk/staff/awaller/disability.a sp

[37] Waller, A. Interactive Communication. In: C Stephanidis (Ed). The Universal Access Handbook. $1^{\text {st }}$ Edition, CRC Press.

[38] Waller, A. and Jack, K (2002). A predictive Blissymbolic to English translation system, In: J. A. Jacko (Ed), Proceedings of ASSETS 2002 (The Fifth International ACM Conference on Assistive Technologies), Edinburgh, Scotland,186-191.

[39] Watson, P. (2006). Bliss Font Creator. Unpublished BSc Honours Dissertation, School of Computing, University of Dundee, Dundee.

[40] Web Accessibility Initiative. 2006. http://www.w3.org/WAI/

[41] WebAIM (2003) An 8-Step Web Accessibility Implementation Model. Retrieved May 9th 2009 from http://www.webaim.org/coordination/implementation 